\title{
High-dose vitamin C therapy: Renewed hope or false promise?
}

\author{
Sarit Assouline, Wilson H. Miller, Jr.
}

$\infty$

See related article page 937

$\mathrm{C}$ omplementary and alternative medicine is commonly used by patients with cancer. Anywhere from $22 \%$ to $69 \%$ of cancer patients may take herbal medicine, medicinal teas, vitamins and minerals, and use visualization techniques. ${ }^{1}$ There is often great pressure put on oncologists by their patients to support the use of and even to prescribe alternative therapies for the treatment of cancer, in particular when no cure or effective therapy exists. Although oncologists might dissuade their patients from pursuing therapies that are likely to be ineffective, in the face of desperate circumstances many patients insist on taking complementary and alternative medicine concurrently with "standard" therapies. A critical concern of most oncologists is whether use of complementary and alternative therapies can cause harm, especially when taken concurrently with a chemotherapy regimen that has a narrow therapeutic index.

But should our concern move beyond adverse events? If a large proportion of patients are interested in alternative remedies that have biologically plausible therapeutic potential, it is the responsibility of conventional medicine to encourage the preclinical and clinical research necessary to demonstrate or refute the efficacy and safety of these treatments, according to the scientific method and rigorous standards set for conventional cancer therapies. ${ }^{2}$

The Office of Cancer Complementary and Alternative Medicine (OCCAM) at the US National Cancer Institute was established in 1998 for this purpose. Not only does it warn people of the harmful effects of some alternative therapies, it also directs them toward available clinical trials of complementary and alternative therapies for cancer and provides peer review and funding for research into these therapies (www.cancer.gov/cam/). OCCAM also provides guidelines to standardize the reporting of cases of effective therapies. This format was used by Padayatty and associates in this issue (page 937) to report on 3 cases where advanced malignant disease was effectively treated with high doses of intravenous vitamin $\mathrm{C}$ therapy. ${ }^{3}$ The detailed and transparent reporting of these cases, with pathologic review by the National Cancer Institute, raises, once again, the possibility that high-dose intravenous vitamin $\mathrm{C}$ therapy may be effective against some cancers.

However, these are only 3 individual cases of very different types of cancer, and in each case there is a possible alternative explanation for the positive outcome. One patient had remission of renal cell carcinoma after vitamin C therapy; however, spontaneous remission has been reported. ${ }^{4}$ This possibility is correctly raised by Padayatty and colleagues.
Another patient, before embarking on vitamin C therapy, underwent a transurethral resection of a stage $\mathrm{T} 2$ transitional cell bladder carcinoma; this treatment alone can result in long-term remission. ${ }^{5}$ In the third case described, a patient with diffuse large B-cell lymphoma refused chemotherapy but received radiation therapy. Radiation was once the standard of care for diffuse large B-cell lymphoma and can lead to long-term remission, at least in earlier-stage cases. ${ }^{6}$ Furthermore, all 3 patients received other forms of complementary and alternative medicine that practitioners of alternative medicine may argue are effective in treating these cancers. Finally, these case reports omit the number of patients who received high-dose intravenous vitamin $C$ therapy with no effect. Because these cases were collected over many years from several institutions, this number may be quite large and the overall response rate quite low. Despite the possible alternative explanations for the favourable outcomes of the 3 patients, Padayatty and associates and $C M A J$ should be commended for publishing detailed case reports so that critical appraisal is possible.

Although previous carefully performed randomized trials of oral vitamin $C$ therapy involving patients with advanced cancer failed to demonstrate any therapeutic benefit, ${ }^{7,8}$ there is recent evidence from laboratory experiments to support the possibility that high-dose intravenous treatment might be more effective. Chen and associates report that vitamin $\mathrm{C}$ levels achievable in vivo only by intravenous infusion are selectively cytotoxic in vitro to various cancer cell lines but not to normal cells by a mechanism involving formation of hydrogen peroxide. ${ }^{9}$ This is consistent with a growing literature that reactive oxygen species play an important role in the mechanism of action of proven cancer treatments and that impaired oxidation-reduction balance in cancer cells might cause induced reactive oxygen species to selectively kill cancer cells. ${ }^{10-12}$ Indeed, additional mechanistic studies may help define tumour types more likely to respond to this and other strategies that induce reactive oxygen species.

There is, therefore, both ample interest and evidence to support research of high-dose vitamin $\mathrm{C}$ administered intravenously as a treatment for cancer. At our institution, we have taken the next step of conducting a phase I trial to establish the safety and dosage of high-dose intravenous vitamin C therapy for patients with advanced cancer; we are collecting preliminary efficacy, quality-of-life and pharmacokinetic data. Numerous pitfalls remain, including defining the most biologically active dose, which tumour types might be most sensitive and the potentially confounding role of additional 
concomitant complementary and alternative medicine. Nevertheless, continued rigorous preclinical and early phase clinical trials of high-dose intravenous vitamin C therapy will provide a scientifically sound basis from which to accept or reject this approach and thus best address the interests and concerns of our cancer patients seeking alternative therapies.

Sarit Assouline and Wilson H. Miller, Jr., are with the Montréal Centre for Experimental Therapeutics in Cancer, Lady Davis Institute for Medical Research, Sir Mortimer B. Davis-Jewish General Hospital, McGill University, Montréal, Que.

Competing interests: None declared.

Contributors: Both authors made substantial contributions to the article, revised it critically for important intellectual content and gave final approval of the version to be published.

Acknowledgement: Wilson H. Miller, Jr., is a Chercheur National of the Fonds de Recherche en Santé du Québec.

\section{REFERENCES}

I. Richardson MA, Sanders T, Palmer JL, et al. Complementary/alternative medicine use in a comprehensive cancer center and the implications for oncology. JClin Oncol 2000; I:2505-I4.

2. Angell M, Kassirer JP. Alternative medicine - the risks of untested and unregulated remedies. NEngl J Med I998;339:839-4I.

3. Padayatty SJ, Riordan HD, Hewitt SM, et al. Intravenously administered vitamin $C$ as cancer therapy: three cases. $C M A J$ 2006;174(7):937-42.

4. Oliver RT, Nethersell AB, Bottomley JM. Unexplained spontaneous regression and alpha-interferon as treatment for metastatic renal carcinoma. BrJ Urol ig89; 63:128-31.

5. Herr HW. Conservative management of muscle-infiltrating bladder cancer prospective experience. J Urol $1987 ; 138: 1162-3$.

6. Kaminski MS, Coleman CN, Colby TV, et al. Factors predicting survival in adults with stage I and II large-cell lymphoma treated with primary radiation therapy. Ann Intern Med I986;104:747-56.

7. Creagan ET, Moertel CG, O'Fallon JR, et al. Failure of high-dose vitamin C (ascorbic acid) therapy to benefit patients with advanced cancer. A controlled trial. $N$ Engl J Med I979;301:687-9o.

8. Moertel CG, Fleming TR, Creagan ET, et al. High-dose vitamin C versus placebo in the treatment of patients with advanced cancer who have had no prior chemotherapy. A randomized double-blind comparison. N Engl J Med i985;312:137-4I.

9. Chen Q, Espey MG, Krishna MC, et al. Pharmacologic ascorbic acid concentrations selectively kill cancer cells: Action as a pro-drug to deliver hydrogen peroxide to tissues. Proc Natl Acad Sci U S A 2005;102:13604-9.

Io. Engel R, Evens AM. Oxidative stress and apoptosis: a new treatment paradigm in cancer. Front Biosci 2006;II:300-I2.

II. McEligot AJ, Yang S, Meyskens FL Jr. Redox regulation by intrinsic species and extrinsic nutrients in normal and cancer cells. Annu Rev Nutr 2005;25:26I-95.

I2. Diaz Z, Colombo M, Mann KK, et al. Trolox selectively enhances arsenic-mediated oxidative stress and apoptosis in APL and other malignant cell lines. Blood 2005; $105: 1237-45$.

Correspondence to: Dr. Wilson H. Miller, Jr., Lady Davis Institute for Medical Research, Sir Mortimer B. Davis-Jewish General Hospital, 3755 Côte Ste. Catherine, Montréal QC H3T IE2; wmiller@ldi.jgh.mcgill.ca

\section{TRADITION}

Since I9II, CMAJ has been committed to advancing the science and art of medicine and promoting public health. 